\title{
frontiers
}

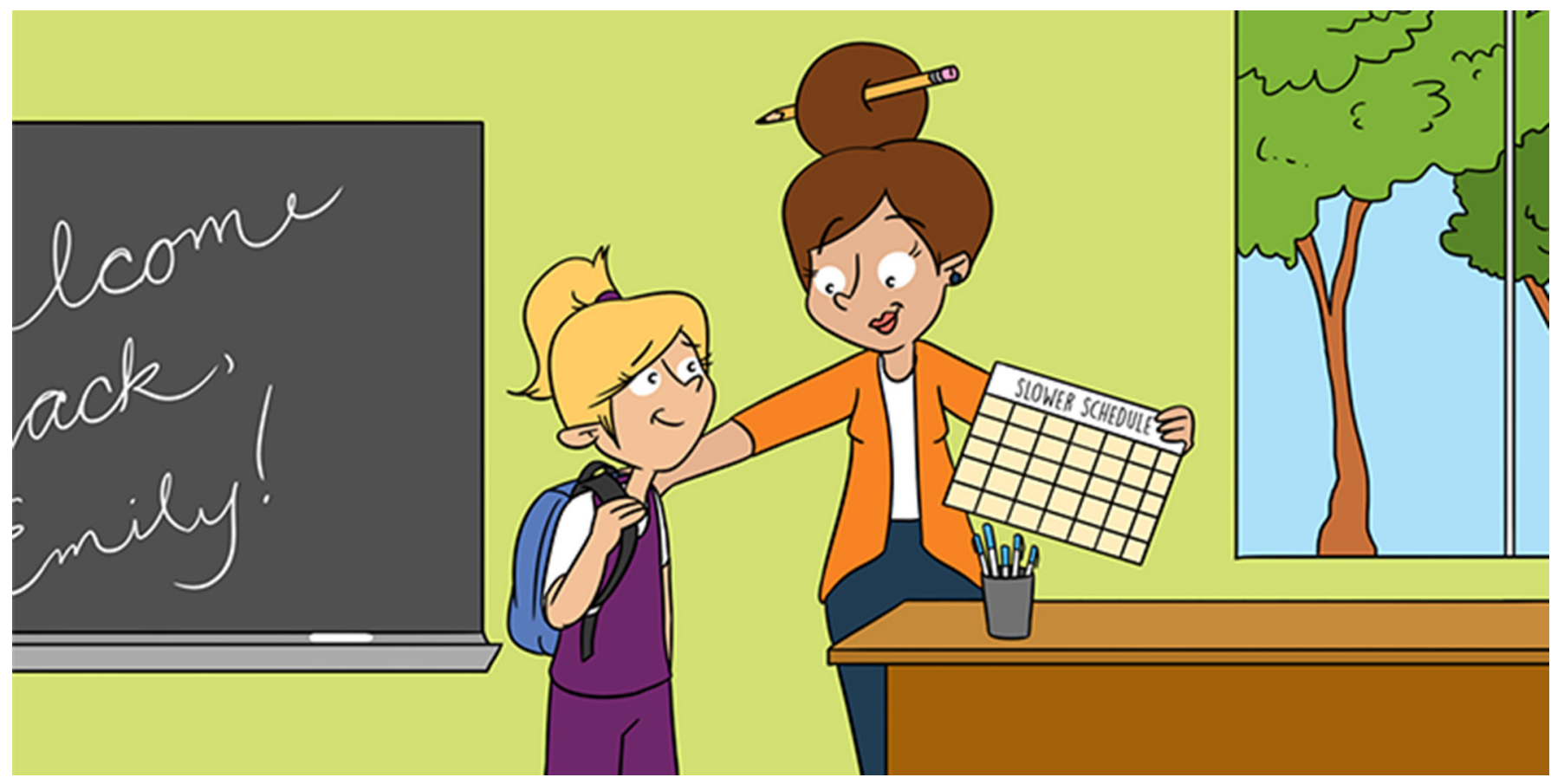

\section{RETURNING TO SCHOOL AFTER A CONCUSSION}

\section{Melissa McCart ", Christina Karns, Meghan Ramirez, Matthew Dawson and Ann Glang}

Center on Brain Injury Research and Training, University of Oregon, Eugene, OR, United States

YOUNG REVIEWERS:

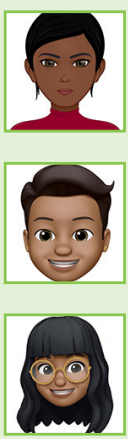

JEANINE

AGE: 15

NAVIN

AGE: 13

RANJANA

AGE: 14
A concussion can occur when someone experiences a hard hit to the head that jars the soft brain. This is why concussions are also called traumatic brain injuries (TBIs). When a student gets a concussion, it often disrupts athletics, school grades, and social life. It can sometimes even cause personality changes. Researchers have learned that: (a) a team approach is best; (b) an individual plan should be developed to help a student return to school successfully; (c) extra supports for learning and play activities at school are important; and (d) parents and teachers need to check a student's progress frequently until there is a full recovery. Concussions can affect you or your friends. You need to know what to do to help yourself get back to play, school, and life. This article summarizes research-based practices for returning to school following concussion.

\section{WHAT IS A CONCUSSION?}

Hey students, skaters, athletes, and bikers! You already know that protecting your brain during any risky activity is important, but injuries happen. What do you do if you think you might have a concussion? 
Figure 1

Average number of yearly trips to the emergency room for concussion, for people 19 years old or younger $[1,2]$. *Vehicles include all types of vehicles (cars, dirt bikes, all-terrain vehicles, etc.). ${ }^{* *}$ Combative includes all types of fighting sports (wrestling, boxing, karate, etc.)

\section{Average Annual Estimates of Emergency Department Visits for Concussion}

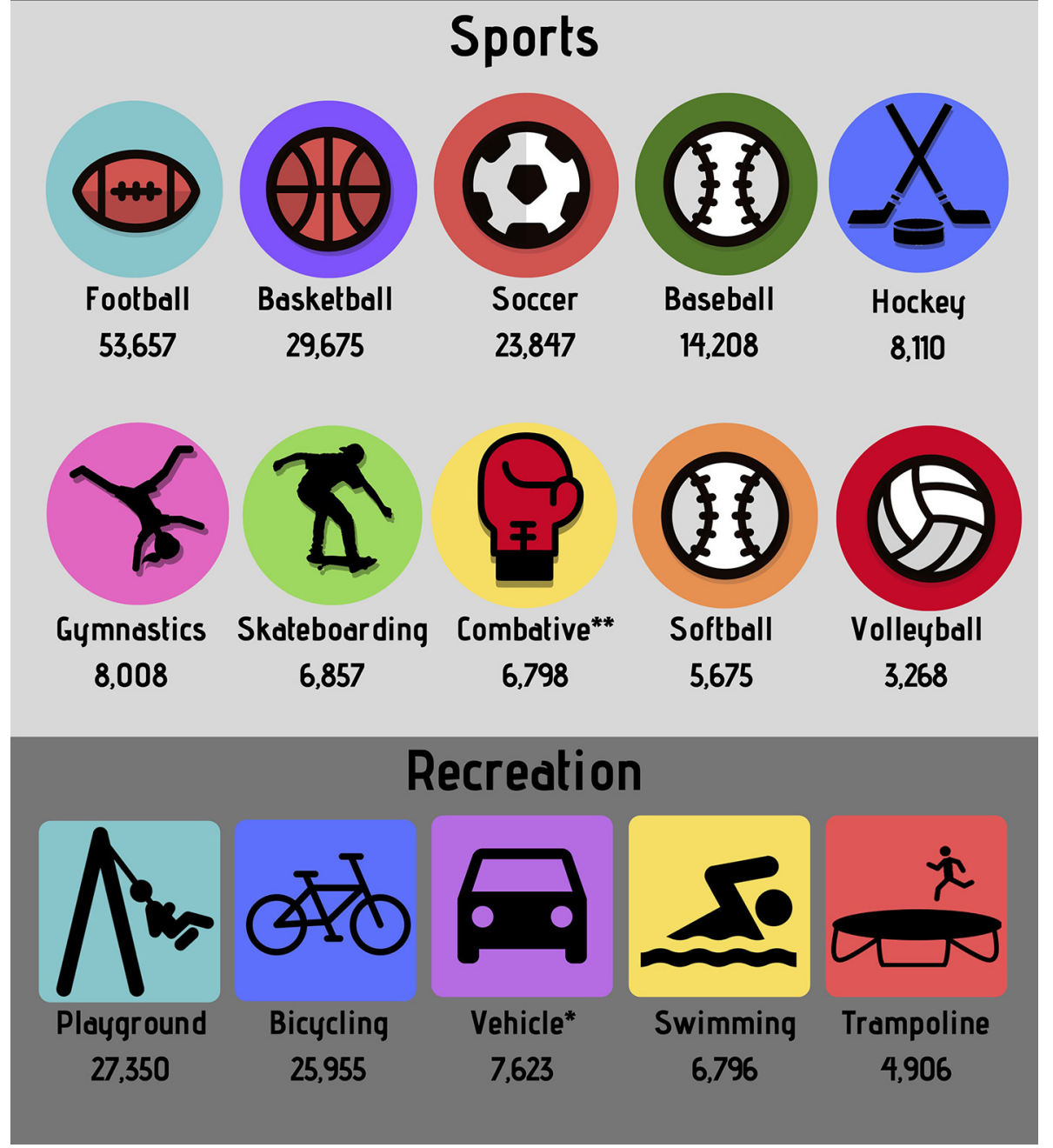

Figure 1

If you get a concussion, how soon should you go back to school and athletics? How long will the concussion affect you? What can teachers, parents, and doctors do to help you recover? In this article, we will give you the latest research-based information about how to get back into the game of life.

A concussion is a brain injury caused by a bump, blow, or jolt to the head or by a hit to the body that causes the brain to move rapidly back and forth inside the skull [1]. Which activities cause the most concussions? Figure 1 shows the number of children who go to the emergency room each year for specific sports and recreation activities that result in concussions. These activities are similar in that they can make the brain twist, bounce, or move violently back and forth in the 
Figure 2

Common

accommodations available at school.

\section{Common School Supports for Students with a Concussion}

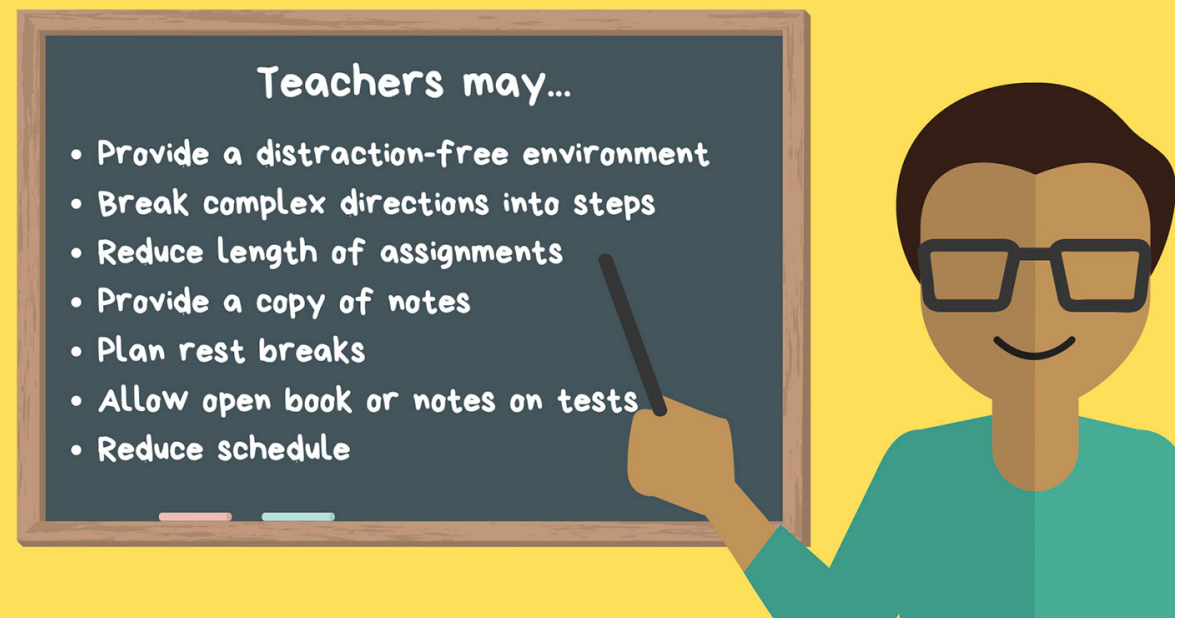

Figure 2

skull, injuring the brain. Concussions can happen in any activity, even on the playground or in your backyard.

Concussions are different from most other types of injuries. Often there is no bump, bruise, or mark when you get a concussion. A strong jolt to the body might not leave a mark. If you break your arm, a doctor will confirm it with an X-ray, but if you get a concussion, there is usually no physical sign of it. This can make it tough when you go back to school after a concussion-you may look fine, but you may feel pretty awful. The symptoms of concussion, which include fatigue, trouble concentrating, and headaches, may make it difficult to keep up on classwork or even to hang out with friends. The good news is that the effects of concussion usually do not last long and there are some strategies that can help you go back to your old self more quickly. Figure 2 lists the common signs of concussion that might be noticed by you or others, like friends, parents, or teachers. Learn more in the Frontiers for Young Minds article called Caring for Your Brain: What You Need to Know about Concussions [3].

\section{EVERY CONCUSSION IS DIFFERENT}

It can be tricky to know when it is ok to return to normal activities after a concussion. You may want to return to school quickly so you do not fall behind or miss important assignments. You may want to get right back to your favorite sports and time with friends. The problem is that it takes most people a few weeks to a month to fully recover 
from a concussion. Research has shown that gradually returning to usual activities like school and sports is important for recovery [4]. Doing too much too soon can make your recovery take longer. Taking it slow allows you, teachers, and parents to learn more about what you need for a successful recovery. Remember, every brain injury is different.

If your symptoms after concussion are manageable, you might just need to take it easy for a few weeks as you return to school. Taking it easy means staying on a regular schedule, going to bed at a reasonable time, and limiting time spent on anything intense, like video games. Just give yourself a mental break while your brain heals. In other words, being bored is a good way to recover from concussion!

\section{A TEAM-BASED APPROACH WORKS BEST}

It is important to tell someone at school right away if you hit your head hard or if a doctor has diagnosed you with a concussion. Working with your family and doctor, the school team can help you figure out the best plan for returning to school and activities. Your decision-making team should include you, your parents or guardians, your doctor, and a school counselor. Sometimes your teacher, administrator, school nurse, or athletic trainer can be on your team as well. The team should work together to create a plan so that everyone is on the same page about your return to school and activities.

\section{EXTRA SUPPORTS ARE IMPORTANT}

Taxing the brain at school with activities, academics, and friends can make recovery take longer.

So, what should a Return to School and Play Plan look like? Although every concussion is different, most students need just a few simple supports in place to help them as their brains recover. These supports

\section{ACCOMMODATIONS}

Accommodations are changes that help students learn when they have challenges. For example, sitting in the front of the classroom or only doing half of an assignment. are called accommodations and may include things like reduced homework, extra time for tests, or delaying big projects or tests until you are feeling better. You might need a special place at school to rest when you get tired, have a headache, or when things get stressful. Here is a detailed list of accommodations that your team can consider. Figure 3 also shows some of the most common accommodations you might get at school.

At home, you might need family support to keep to a low-key schedule. You might need your family to be sure you have a quiet space and to help you make it to your doctor appointments, get to sleep on time, and eat healthy meals. In sports, your coach will need to know how you are feeling and encourage you to take it easy so that you do not get worse or get another concussion. 
Figure 3

Common signs of concussion.

\section{Signs of Concussion}

Reported by student:

- Headache

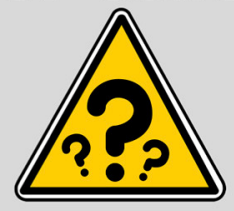

- Fatique

- Blurry vision

- Feels sluqgish

- Feels foggy

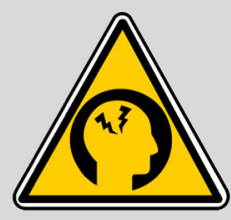

- Appears dazed

- Exhibits confusion

- Forgets plays in sports

- Unsure about facts

- Sensitivity to light and noise

- Problems concentrating

- Problems remembering

- Difficulty sleeping

- Feeling down

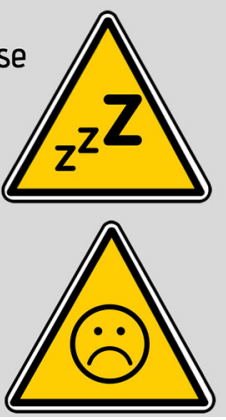

- Moves clumsily

- Personality change

- Responds slowly

- Forgets events

\section{TRACK YOUR PROGRESS}

It is important to track your progress so you, your family, your coaches, and your teachers know if you are getting better and what things you might need help with. There are lots of ways you can track your own progress and communicate how you are doing. You could keep a journal or do a daily survey. There are even apps specifically designed to help young people track their symptoms after a brain injury [5]. Something as simple as a happy-to-sad face rating system can give everyone a sense of how things are going for you each day.

Regardless of what kind of tracking system you use, it is important to let people know how you are doing. After a concussion, teachers might be not aware of what you are struggling with, because you look just like you did before your concussion. For example, your math teacher might not know that each night your homework takes over an hour, whereas before you could get it done in $15 \mathrm{~min}$. This information helps your teachers and the rest of the team know what accommodations will be the best to help you.

\section{WHAT IF I HAVE ONGOING PROBLEMS?}

Most students will recover from a concussion within a few weeks, so accommodations will be temporary. In some cases, recovery takes longer and more accommodations might be needed. There are 


\section{PLAN}

A 504 plan is a formal legal plan that requires a student to be given the defined accommodations that are agreed upon by the students' team.

INDIVIDUALIZED EDUCATION PLAN (IEP)

A formal legal plan that provides for special instruction and is designed to specifically address a student's individual learning needs two programs to help you get the longer-term supports you might need. A $\mathbf{5 0 4}$ plan is for students with a disability that limits major life activities like recreation and schoolwork. If you find you need ongoing accommodations but you can do most of your schoolwork and responsibilities by yourself, a 504 plan might be right for you. If you need more help, an individualized education plan, or IEP, could be best. Your team will need to work together to coordinate what kind of plan is best for you.

It is important to be informed about managing concussions so if it happens to you, you will know what to do to support your recovery. The most important thing to remember is that a gradual return to academics and activities, as long as it does not make things worse, is the best approach. If you follow this guideline, you will be back in the game of school, sports, and life as quickly as possible!

\section{AUTHOR CONTRIBUTIONS}

MM was the lead author. CK and AG were the contributing authors. $M D$ and MR were students and contributed to the first draft of the manuscript. All authors contributed to the manuscript, read, and approved the submitted version.

\section{REFERENCES}

1. Centers for Disease Control and Prevention. 2017. Returning to School After a Concussion: A Fact Sheet for School Professionals. Available online at: https://www.cdc.gov/headsup/pdfs/schools/tbi_returning_to_school-a.pdf

2. Sarmiento, K., Thomas, K. E., Daugherty, J., Waltzman, D., Haarbauer-Krupa, J. K., Peterson, A. B., et al. 2019. Emergency Department visits for sports- and recreation-related traumatic brain injuries among children-United States, 2010-2016. MMWR Morb. Mortal. Wkly. Rep. 68:237-42. doi: 10.15585/mm wr.mm6810a2

3. Ketcham, C., and Hall, E. 2016. Caring for your brain: what you need to know about concussions. Front. Young Minds 4:17. doi: 10.3389/frym.2016.00017

4. McCrory, P., Meeuwisse, W., Dvorak, J., Aubry, M., Bailes, J., Broglio, S., et al. 2017. Consensus statement on concussion in sport-the 5 th international conference on concussion in sport held in Berlin, October 2016. Br. J. Sports Med. 51:838-47. doi: 10.1136/bjsports-2017-097699

5. Dexheimer, J. W., Kurowski, B. G., Anders, S. H., McClanahan, N., Wade, S. L., Babcock, L. 2017. Usability evaluation of the SMART application for youth with mTBI. Int. J. Med. Inform. 97:163-70. doi: 10.1016/j.ijmedinf.2016.10.007

SUBMITTED: 05 September 2019; ACCEPTED: 06 February 2020; PUBLISHED ONLINE: 28 February 2020.

EDITED BY: Robert T. Knight, University of California, Berkeley, United States 
CITATION: McCart M, Karns C, Ramirez M, Dawson M and Glang A (2020) Returning to School After a Concussion. Front. Young Minds 8:20. doi: 10.3389/ frym.2020.00020

CONFLICT OF INTEREST: The authors declare that the research was conducted in the absence of any commercial or financial relationships that could be construed as a potential conflict of interest.

COPYRIGHT (c) 2020 McCart, Karns, Ramirez, Dawson and Glang. This is an open-access article distributed under the terms of the Creative Commons Attribution License (CC BY). The use, distribution or reproduction in other forums is permitted, provided the original author(s) and the copyright owner(s) are credited and that the original publication in this journal is cited, in accordance with accepted academic practice. No use, distribution or reproduction is permitted which does not comply with these terms.

\section{YOUNG REVIEWERS}
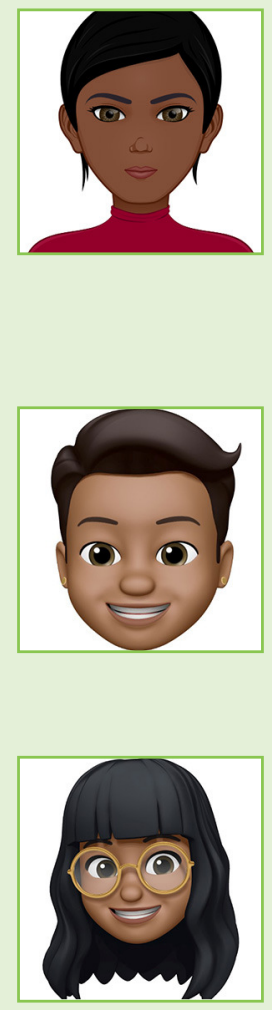

\section{JEANINE, AGE: 15}

I am a junior at a very competitive school which means that I always have to be prepared for what comes next. My favorite subjects are molecular biology and chemistry even though I also enjoy math and art history. Also, I enjoy swimming and being a member of the environmental club and track and field team. In addition, I make time to have lots of fun. My hobbies include, reading fantasy books, watching documentaries, hanging out with my friends, and eating my favorite foods.

\section{NAVIN, AGE: 13}

I am interested in the medical field and aspire to become an anesthesiologist in the future. I enjoy reading and drawing cartoons. I have been playing ice hockey and love being on the rink. Tennis, swimming, and cross-country are also my favorite sports. I love eating anything that is vegetarian. I want to contribute to my community in any way I can and make a positive change.

\section{RANJANA, AGE: 14}

I love science and am especially into medicine. I am passionate about health and wellness. I enjoy reading and watching heist movies. I love spending time in labs, researching, and learning. I would like to learn more languages; right now, I can speak three. I hope to travel to more countries in the future!

\section{AUTHORS}

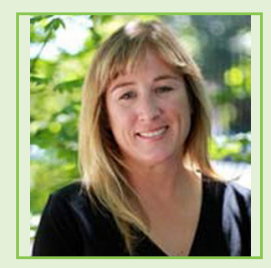

\section{MELISSA MCCART}

Melissa McCart earned her doctorate, masters' degree, and administrator's licenses from the University of Oregon. She has worked with at-risk children and families as a behavior specialist and special education teacher. She is currently the director of the Oregon TBI Teams and works in the field of TBI research at the Center on Brain Injury Research and Training at the University of Oregon. Melissa has been a school administrator, behavioral consultant, and a special education 

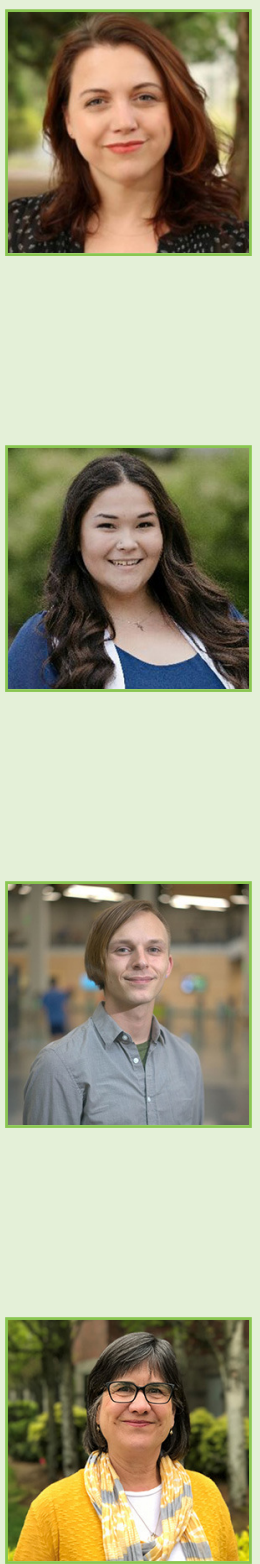

teacher to students with emotional/behavioral disorders. Melissa currently is a member of the National Collaborative on Childhood Brain Injury and serves on multiple committees. *mccartauoregon.edu

\section{CHRISTINA KARNS}

Christina Karns received her doctorate in Neuroscience from the University of California, Berkeley. At the University of Oregon, she has directed neuroimaging projects with children, teens, and adults with and without disability to clarify how attention and self-regulation support healthy brain development. This work has provided foundation for evidence-based interventions that utilize the neuroplasticity of emotions and cognition to support people in positive and healthy interactions with society and each other.

\section{MEGHAN RAMIREZ}

Meghan Ramirez is a student working with the Center on Brain Injury Research and Training in Eugene, Oregon. She is currently a senior at the University of Oregon studying psychology and minoring in anthropology and sociology. She is part of ongoing research with the Center on Brain Injury Research and Training as well as with the Brain Electrophysiology Lab. Her research interests are in the therapeutic benefits of sound and how they can be used as treatment for individuals with traumatic brain injuries.

\section{MATTHEW DAWSON}

Matthew Dawson is completing his final year as an undergraduate at the University of Oregon. Double majoring in biology and psychology, Matthew's focus has been in neuroscience. His undergraduate career has been spent working with Center on Brain Injury Research and Training on the TBI Teams project focused on providing evidenced-based practices for educators working with students who have experienced TBI. Matthew wants to further explore the implications of TBI on unaccompanied youth and adolescents experiencing homelessness.

\section{ANN GLANG}

Ann Glang is a Research Professor and Director of the Center on Brain Injury Research and Training at the University of Oregon. Since 1987, she has secured and directed or co-directed over 30 federally funded research projects focused on individuals with TBI. She has published numerous journal articles, edited two books on her work with children with TBI, and co-authored five manuals for educators serving children with TBI. Dr. Glang was awarded the 2011 Researcher of the Year award by the North American Brain Injury Society. Dr. Glang has also led the development of a range of SBIR-funded education programs, including Brain 101, a concussion education and management program for high schools. 